\title{
Introduction: setting the scene
}

This book discusses a topic that touches us all, namely, food safety and food hygiene. We all have to eat and we are all to some extent dependent on others to ensure that the food we eat does not harm us. Modern food chains are complex. Food is big business and it is a truly global business. The food we buy in our supermarkets, corner shops, restaurants and cafes may have travelled thousands of miles before it reaches us. It may also have been handled by a chain of people upon whom we rely to ensure that the produce we receive is safe. Food is not only a significant part of our economy and our social lives, it also has profound significance for our wellbeing (see Chapter 2). In this book we focus on two major sectors of the food chain, food retailing and food hospitality, and we examine one food governance regime, namely, that pertaining to food safety and food hygiene.

\section{RISK}

This book is about risk, in particular the prevention of the risks associated with food safety/hygiene. There have been a number of very high profile food risk disasters in the lifetime of readers of this book, for example, the bovine spongiform encephalopathy (BSE) crisis and cases of $E$. coli fatalities (see Chapter 4). But the most common manifestations of food safety/hygiene risks are low level and undramatic episodes, typically upset stomachs leading to a day or two off work. These are events which may not even be traced back to food, while the effects may occur within hours or take days to appear and thus there may be uncertainty about the cause of the illness. The ill-effects also depend upon our general state of health, with some vulnerable groups being at high risk and generally healthy people left relatively unaffected (see Chapter 3 ). Overall, however, the cumulative effects of these episodes may be very costly to our health systems and most particularly to economic productivity and happiness.

The causes of these episodes are often routine and mundane in their origin. These are not high-tech failures. They can often be traced back to low key failures such as food handlers not washing their hands before touching food, or failing to separate cooked and uncooked meats, or not checking food storage 
temperatures and sell by dates. Our concern in this book is on the governance systems in place to protect us from the risks to which we are involuntarily exposed by others who handle the food they sell to us in the retail and catering sectors in the UK. In particular, we focus on the understandings of risk and risk governance held by those within the industry and governance regime rather than impose formal definitions of risk on respondents.

\section{RISK REGULATION/GOVERNANCE}

Business organizations in the food retail and catering sectors are subject to a food governance system which comprises the state and a variety of non-state influences. How the state intervenes to manage food safety/hygiene risks is one focus of this book. Food is a topic which attracted early state intervention through regulation. Food laws and institutions to implement these laws can be traced back to the nineteenth century (see Chapter 4). We know from the existing socio-legal literature on regulation that state regulation is 'necessary but not sufficient' as an influence on business risk management practices. We also know that a broader food governance system has emerged, embracing organizations and groups beyond the state (see Chapter 5). What is not clear is the relative importance of these other groups, in relation to each other and in relation to state regulation.

Risk regulation since the late twentieth century has increasingly been understood to include sources of regulation beyond the state. State regulation has gradually co-opted more non-state bodies into its regulatory activities. It has also experimented with new ways of managing risks which fall outside traditional public policy approaches, a prime example being the adoption of private sector risk management tools and perspectives. So we have seen relatively mundane food risks become subject to technical risk-based regimes (see Chapter 4). How able food businesses are to comprehend and implement these systems is a question posed by the findings presented in this study (see Chapter 6).

\section{THE RESEARCH}

The evidence in this book is a snapshot of one sector in one country at one moment in time. In order to make sense of these data and their implications it is necessary to compare them to other studies in the research literature. Indeed, the research design sought to develop previous research in a number of respects. For example, the last research project I undertook considered the 
impact of state regulation on one large nationalized business, British Railways (Hutter 2001; see also Chapter 2). The project forming the basis of this book examines the impact of a broader governance regime on a sector comprising very different business organizations - so the focus is more on inter-organizational than intra-organizational variation.

This research uses the empirical data we collected to connect theories about the governance of risk to the routine and often mundane food hygiene/safety practices of those on the shop floor. It considers the understandings of those in the industry about the role of the state and its influence on the risk management practices of business organizations and their employees. This necessarily involves exploration of the tensions between control, empowerment and responsibility. How far does the state endeavour to control business risk management practices? And how is this balanced against empowering businesses with responsibility for managing the risks they generate? The research looks beyond state regulation to consider broader governance regimes. These cover economic actors such as insurance companies and trade associations, and civil society actors such as non-governmental organizations and citizens. An important objective of the book is to explore how these risk governance regimes shape organizational risk management practices and the responses and routines of those employed within them.

Chapter 1 will consider the academic context of the research and its theoretical setting. In Part I, Chapter 2 considers the food retail and hospitality sectors in the UK, and the research approach used in collecting the empirical data for this study. Chapter 3 focuses on the food hygiene/safety risks associated with the food retail and hospitality sectors. It considers the official data and also findings from the empirical analysis, in this case examining the understandings of risk held by those working in the industry. Part II considers the risk regulation regime in place to govern food safety/hygiene in the UK. Chapter 4 considers the state regulatory regime, Chapter 5 the governance regime that exists beyond the state and Chapter 6 the risk regulation regimes put in place within organizations. In all of these chapters the empirical evidence of this research will be considered alongside the existing literature. Part III draws out the theoretical and policy implications of the research, considering in particular what prompts businesses to manage risk and the implications of these findings for contemporary food governance and regulatory policy making. 